\title{
A Comprehensive Review of Embedded Transmission Pricing Methods Based on Power Flow Tracing Techniques
}

\author{
Baseem Khan and Ganga Agnihotri \\ Department of Electrical Engineering, Maulana Azad National Institute of Technology, Bhopal 462003, India \\ Correspondence should be addressed to Baseem Khan; baseem_khan04@yahoo.com
}

Received 2 August 2013; Accepted 22 August 2013

Academic Editors: Z. Gu and Z. Li

Copyright ( 2013 B. Khan and G. Agnihotri. This is an open access article distributed under the Creative Commons Attribution License, which permits unrestricted use, distribution, and reproduction in any medium, provided the original work is properly cited.

Restructuring of electricity supply industry introduced the concept of deregulation. After deregulation transmission cost allocation is a vital issue. In the available literature, various authors have presented different methods for allocation of transmission cost. This paper presents the review of a variety of methods and algorithm based on the principle of power-flow tracing. For a fair and equitable transmission charge allocation it is necessary to know the quantum of power flowing by each generator and load in line flows. Power flow tracing techniques are mainly based on the concepts of proportional sharing principle, graph theory, circuit theory (Z-bus tracing), optimization approach, relative electrical distance concept, Equilateral bilateral exchange (EBE), and game theory. This paper presents a comprehensive review of all the available literature on the above.

\section{Introduction}

Restructuring of electricity supply industry (ESI) has taken place around the world. The main aim behind this restructuring is to introduce competition to increase efficiency and quality of services in the electricity supply industry. Initially, power sector operated as vertically integrated utility in which all the functions are governed and controlled by state own organization. After the restructuring deregulation and open access is introduced in the ESI. Following deregulation the regulated structure of the ESI is converted into a deregulated structure in which all the three major functions are separated by three companies, namely, Generation Company Ltd. (GENCOS), Transmission Company Ltd. (TRANSCO), and Distribution Company Ltd. (DISCOMS). Competition is introduced in the entire system. Various independent power producers IPPs come in the field of generation. They generate power and sell to the Central Transmission Utility (CTU) or TRANSCO. Competition is introduced in the distribution sector. But it is difficult to introduce competition in the transmission sector due to its monopolistic nature. In transmission sector, it is not possible to build a separate transmission line for every generation facility. Hence transmission cost allocation is very complicated task in the deregulated environment.
Several methodologies and their variants are presented to solve this problem.

The main aim of any transmission pricing methodology is to introduce a fair competition in the electricity sector and provide efficient economic signals. Transmission pricing methods are the overall processes of translating transmission costs into overall transmission charges. Figure 1 presents the charging strategy for transmission utility.

The main transmission pricing methodologies are classified as in Figure 2.

Further, the incremental pricing methods are subdivided into categories as in Figure 3.

Colombia, UK, and Brazil have used long, run marginal cost (LRMC) methodology due to its easy implementation.

Embedded Transmission Pricing Methods allocate the embedded system costs, that is, fixed cost among transmission system users. These methods can be classified as in Figure 4.

Selection of the slack bus greatly influenced the pricing methodologies, for example, use of a fixed "slack bus" is adequate in countries where most of the load is concentrated in a single center, such as the cities Buenos Aires (Argentina) and Santiago (Chile). Hence the marginal participation method is applied in countries like Argentina, Chile, and Panama. 


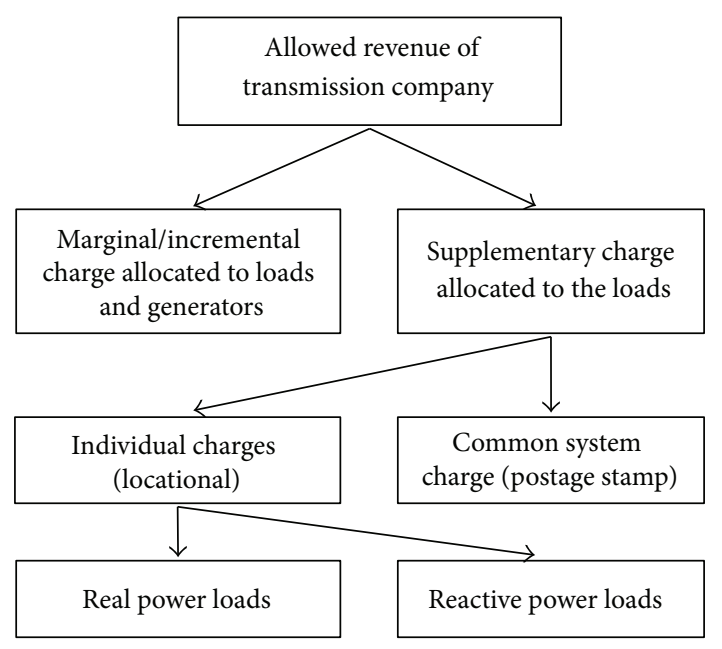

FIgURE 1: Charging strategy.

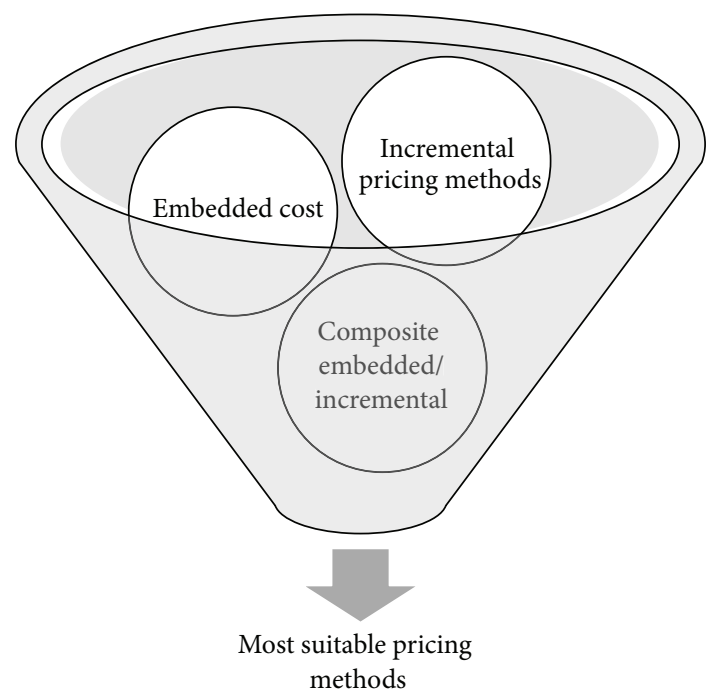

FIgURE 2: Various transmission pricing methods.

In India, the method which is used so far is postage stamp method. But this method is not distance and direction sensitive. It is mainly depending on the amount of transacted power. The main advantage of this method is its simplicity in implementation. Due to its various demerits, central electricity regulatory commissions (CERCs) of India proposed a new transmission pricing methodology, which is the combination of power flow tracing technique and marginal participation methodology. In the proposed hybrid methodology power flow tracing is used for selection of the "slack bus" while by marginal participation, burden of transmission charges or losses on each node is computed.

This paper presents the review of the various methods and techniques based on power flow tracing which is used for the transmission embedded cost allocation in the electricity market. For the fair and equitable allocation of the transmission usage, it is necessary to trace the path of power supplied from the generator to load, though it is difficult, but by the power

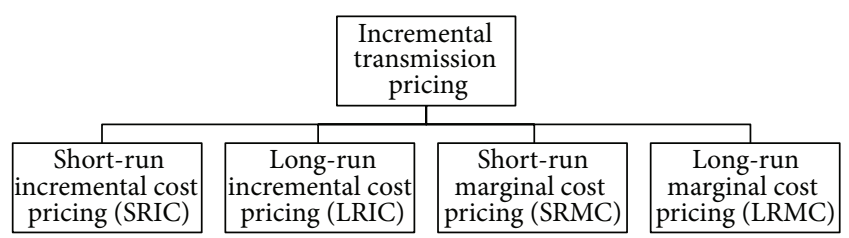

Figure 3: Types of incremental transmission pricing methods.

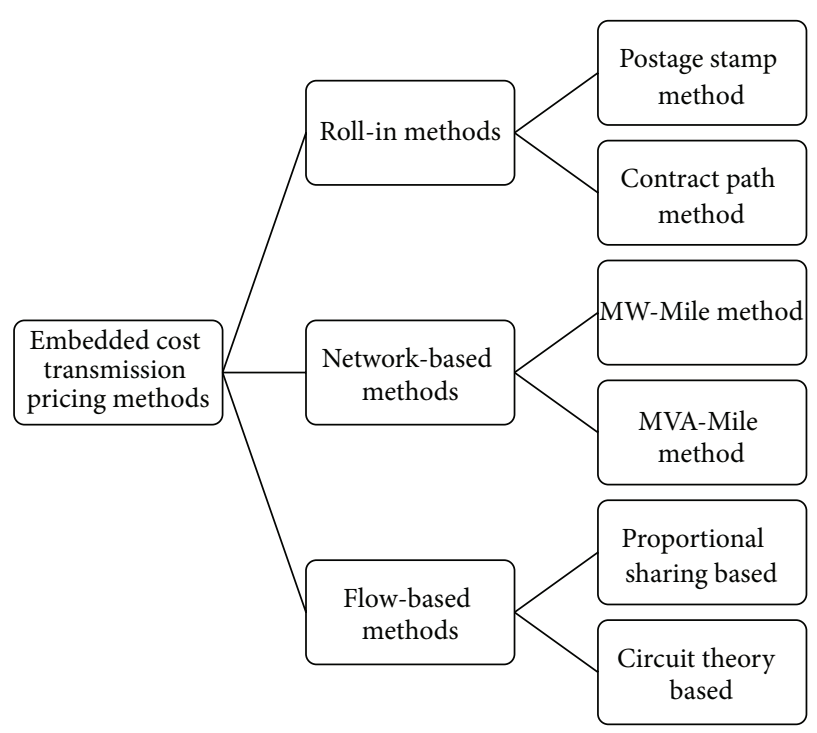

FIGURE 4: Types of embedded transmission pricing methods.

flow tracing the flow of electricity can be traced. The main principle used in power flow tracing is proportional sharing principle. According to this principle a network node work as a perfect mixer which follows the Kirchhoff current law, that is, total incoming power is equal to total outgoing power. The principle described, assumes that each outflow (a flow leaving a node) on a line is dependent only on the voltage gradient and the impedance of the line. The contribution of each inflow (a line flow entering the node) to each outflow is in the same proportion as the inflow on each line divided by the total inflow of all lines at the node. However, a disadvantage is the fact that the proportional sharing principle for power transfer between generators and loads is not based on a mathematically strict derivation [1].

The rest of the paper is organized as follows: from Sections 2 to 8 authors present the review of various methods based on or using power flow tracing. In Section 9 case studies related to practical implementation of power flow tracing techniques are presented. Section 10 provides a comparison between various power flow tracing techniques. Discussion is also done in this section followed by the conclusion.

\section{Power Flow Tracing Techniques Based on Proportional Sharing Principle}

This approach allocates the charges of each transmission facility to a wheeling transaction based on the extent of use of that facility by the transaction. This is determined as a function 
of magnitude, the path, and the distance travelled by the transacted power.

\subsection{Topological Generation Distribution Factors Based Power} Flow Tracing (Bialek Tracing). This algorithm works only on lossless flows when the flows at the beginning and end of each line are the same. The tracing of electricity is done by upstream looking algorithm and downstream looking tracing algorithm.

2.1.1. Downstream Looking Algorithm. In the downstream looking algorithm the nodal power $P_{i}$ is expressed as the sum of the outflows

$$
P_{i}=\sum_{l \in \alpha_{i}^{\{d\}}}\left|P_{i-l}\right|+P_{L_{i}}=\sum_{l \in \alpha_{i}^{\{d\}}} c_{l i} P_{l}+P_{L_{i}}, \quad \text { for } i=1,2,3, \ldots, n,
$$

where $\alpha_{i}^{\{d\}}$ is the set of nodes supplied directly from node $i$, $P_{i-l}$ is the line flow in line $i-l, P_{L_{i}}$ is the load at node $i$ and $c_{l i}=\left|P_{l-i}\right| / P_{l}$. This equation can be written as

$$
P_{i}-\sum_{l \in \alpha_{i}^{\{d\}}} c_{l i} P_{l}=P_{L_{i}} \quad \text { or } \quad A_{d} P=P_{L}
$$

where $A_{d}$, is the $(n \times n)$ downstream distribution matrix and $P_{L}$ is the vector of nodal demands. The $(i, l)$ element of $A_{d}$, is equal to

$$
\left[A_{d}\right]_{i l}= \begin{cases}1 & \text { for } i=l \\ -c_{l i}=-\frac{\left|P_{l-i}\right|}{P_{i}} & \text { for } l \in \alpha_{i}^{\{d\}} \\ 0 & \text { otherwise }\end{cases}
$$

Note that $A_{d}$ is also sparse and nonsymmetric. If $A_{d}^{-1}$ exists then $P=A_{d}^{-1} P_{L}$ and its $i$ th element is equal to

$$
P_{i}=\sum_{k=1}^{n}\left[A_{d}^{-1}\right]_{i k} P_{L k} \quad i=1,2, \ldots, n .
$$

This equation shows how the nodal power $P_{i}$ distributed between all the loads in the system. On the other hand, the same $P_{i}$ is equal to the sum of the generation of node $i$ and all the inflows in lines entering the node. Hence, the inflow to node $i$ from line $i$ - $j$ can be calculated using the proportional sharing principle as

$$
\begin{aligned}
\left|P_{i-j}\right| & =\frac{\left|P_{i-j}\right|}{P_{i}} P_{i}=\frac{\left|P_{i-j}\right|}{P_{i}} \sum_{k=1}^{n}\left[A_{d}^{-1}\right]_{i k} P_{L k}, \\
& =\sum_{k=1}^{n} D_{i-j, k}^{L} P_{L K} \quad \forall j \in \alpha_{i}^{\{u\}},
\end{aligned}
$$

where $D_{i-j, k}^{L}=\left|P_{i-j}\right|\left[A_{d}^{-1}\right]_{i k} / P_{i}$ is the topological load distribution factor, that is, the portion of $k$ th load demand that flows in line $i-j$.
The generation at a node is also an inflow and can be calculated using the proportional sharing principle as

$$
P_{G i}=\frac{P_{G i}}{P_{i}} P_{i}=\frac{P_{G i}}{P_{i}} \sum_{k=1}^{n}\left[A_{d}^{-1}\right]_{i k} P_{L K} \quad \text { for } i=1,2, \ldots, n .
$$

This equation shows that the share of the output of the $i$ th generator used to supply the $k$ th load demand is equal to $P_{G i} P_{L k}\left[A_{d}^{-1}\right]_{i k} / P_{i}$ and can be used to trace where the power of a particular generator goes to [2].

This methodology is proposed by Bialek and Tam in March 1996 [3] which explained the method for tracing generator's output. They introduce a simple topological method of tracing the flow of real and reactive power in transmission networks. Bialek also explained the topological tracing method for apportioning of the total transmission loss to individual sinks or sources [2, 4], whereas in August 1997 [5], explained the topological generation and load distribution factors for supplement charge allocation in transmission open access. Also in August 1998, same author [6] explained the MW-Mile methodology to allocate the transmission supplementary charges to real and reactive power loads.

In July 1999, Kattuman et al. [7] explained a transmission loss allocation scheme based on the concept of power flow tracking and also proportionality assumption is analyzed in terms of the cooperative game theory. Bialek also dealt with the transmission pricing of cross-border trades $[8,9]$. In October 2000, Li et al. [10] explained a power flow tracing method which is based on topological distribution factors. On Sep 2001, Su and Liaw [11] explained a new wheeling pricing technique called MVA-KM method, which applies AC power flow and considers the apparent power. In June 2002, Al-Rajhi and Bialek [12] explained the comparison between the marginal and tracing charging of transmission. In August 2003, Limpasuwan et al. [13] investigated the application of electricity tracing methodology in Thailand. In August 2002, Bialek [14] explained a range of indices to quantify the incentives for gaming the uniform-price spot market. In October 2002, Shirani and Siahkali [15] explained the application of power flow tracing algorithm to allocate the congestion cost in the pool market. In 2004, Limpasuwan et al. [16] explained the Transmission Use of System charge (TUOS) methodology suggested by Price water house Cooper $(\mathrm{PwC})$ and makes a comparison with a transmission pricing method based on a combination of the electricity tracing and Long Run Average Incremental Cost (LRAIC). In May 2004, Kattuman et al. [17] explained that the allocation done by the tracing methodology is equal to the Shapely value of an equivalent cooperative game. In June 2003, Bialek and Ziemianek [18] explained a comparison between the graph based tracing algorithm with the algorithm based on the solution of linear equations and declared that the algorithms are conceptually the same. Also a practical algorithm is presented to eliminate the cycles from the diagraph of flows. In July 2004, Bialek and Kattuman [19] rationalized proportional sharing principle of cooperative game theory and information theory. They concluded that Shapely value validates the proportional sharing rule. In June 2005, Adsoongnoen et al. [20] enlightened a unified transmission pricing based on electricity tracing methodology 
of cross border trades. In [21] Nallagownden et al. extends the methods of proportional sharing and put forward an algorithm to determine the extent of use of a transmission path and associated losses. In December 2009, Pal et al. [22] explained an analytical approach for calculating the incentive charge for individual participant when the multiple wheeling transactions are considered simultaneously. In May 2010, Achayuthakan et al. [23] furnished tracing in a new way of representing the inverted tracing upstream and downstream distribution matrices in the form of matrix power series. In June 2010, Nallagownden and Lee [24] explained tracing methodology for the purpose of eliminating problems related to the Marginal pricing of transmission costs. In July 2010, Naresh et al. [25] explained the Genetic algorithm based approach for power flow tracing and compared with existing approaches.

\subsection{Factors Based on Generators Domain (Kirschen Tracing).} The domain of a generator represents a subset $N$ of $n$ buses, which are supplied by this generator. A particular bus belongs to a generator domain if there is a "trace" through the transmission network for which the direction of power flow is from the generator to the bus. The generator common is a subset of "neighbored" buses from the subset $N$, which are supplied by the same generators. The subsets of buses which are not connected and not supplied by the same generators are treated as separate commons. A bus therefore belongs to only one common. The branches can be divided in two groups: those which connect two buses which are part of the same common (the internal branches) and those which connect two buses which belong to different commons (the external branches). External branches are called a link.

Knowing the direction of the power flow through the network elements and the commons and the links being defined, the graph theory can be applied. The state graph of the problem studied can be obtained using the following representation conventions: the graph vertices correspond to the commons, graph arcs correspond to links between the commons and the arc orientation is given by the power flows. The state graph provides only a qualitative view of the power system. The inflow of a common is defined as the sum of the injected power by the sources connected to buses located in this common and the power imported in this common from other common by links.

The calculus of generator contribution to various commons ( $D$ is the set of commons) is made in the following manner [26]:

$$
\begin{gathered}
P_{j k}^{i}=w_{j}^{i} \cdot P_{j k}, \\
w_{k}^{i}=\frac{\sum_{j \in D} P_{j k}^{i}}{P_{k}}, \quad k \in D, \\
P_{k}=\sum_{j \in D} P_{j k}, \quad k \in D \backslash j,
\end{gathered}
$$

where $w_{j}^{i}$ is the contribution of the $i$ generator to the load and the outflow of the $j$ common; $w_{k}^{i}$ is the contribution of the $i$ generator to the load and the outflow of the $k$ common; $P_{j k}$ is the flow on the link between the $j$ and $k$ commons; $P_{j k}^{i}$ is the flow on the link between the $j$ and $k$ commons due to the $i$ generator; $P_{k}$ is the inflow of the $k$ common.

In February 1997, Kirschen et al. [26] explained a power flow tracing method based on the proportional sharing assumption which introduces the concept of domains, commons, and links. On the same track a case study has been discussed for normal and network contingency conditions in [27] by Thukaram et al. June 2006. In May 1998, Strbac et al. [28] explained the method based on the generator domain distribution factors to allocate the usage of branch to the load and generators in the maximum flow conditions. In November 1999, Kirschen and Strbac [29] explained the method of real and reactive power tracing by converting the all power injections into real and imaginary currents.

2.3. Nodal Generation Distribution Factors. In Nov 2000, Gubina and Orgie [30] explained the method to determine the generators' contribution to a particular load by using the nodal generation distribution factors (NGDF-s). In Dec 2000, Grgic and Gubina [31] explained the distribution factor approach for the reactive power flow tracing. Pantoš et al. in 2003-04 worked on transaction based transmission service pricing techniques based on the Nodal Generation Distribution factor and also proposed an Ex-Ante transmission pricing technique. They also proposed a new power flow tracing method and explained a transmission service pricing. The same authors further proposed a pattern based transmission pricing technique [32-36].

\section{Power Flow Tracing Techniques Based on Graph Theory}

In January 2000, Sun et al. [37] explained a new method for tracing AC power flows where the graph theory is used to solve the tracing problem. In April 2000, Xi-Fan et al. [38] explained a very efficient algorithm for power flow tracing by proposing two current decomposition axioms in which Graph theory is used whereas Wei et al. [39] used graph theory to analyze real power transfer between individual generators and loads. In Aug 2000, Wu et al. [40] explained the use of graph theory to calculate the contributions of individual generators and loads to line flows and the real power transfer between individual generators and loads. In March 2001, Chai and Sekar [41] explained a methodology using graph theory to determine the specific generator contributions to different loads and the transmission system usage of different utilities. In Dec 2001, Wei et al. [42] proposed that the graph theory is used to detect the existence of circulating power then the optimal power flow approach is applied to eliminate circulating power. From 2003 to 2009, Xie et al. proposed and explained the power flow tracing algorithms founded on extended incidence matrix and matrix multiplication considering loop flows $[1,43,44]$. In July 2003, Ghasemi et al. [45] explained the closed-form solution for tracing problem by presenting a formula which is obtained by using both proportionality and averaging criteria. From 2004 to 2010, Mustafa et al. proposed power flow tracing method based on tracing currents and complex power flows. They also 
proposed a proportional tree method based method for tracing. A comparison has also done by the same authors [46-48]. In Oct 2004, Xiao and Wang [49] explained a proportional tree method to determine the contribution of an individual generator to loads, and also to determine the nodal-must-run-share. In Dec 2005, Wang and Xiao [50] explained proportional tree methods, to allocate and price the transmission usages among the users. From 2005 to 2008, Lim et al. explained power flow tracing and loss allocation method based on loop flow analysis [51-53]. In 2006, Su et al. proposed a method to deal with the problem of reactive power decomposition where Graph theory and proportional sharing principle are employed to determine the power flow tracing sequence $[54,55]$. From 2006 to 2009, Abdelkader proposed and explained various power flow tracing techniques and loss allocation algorithms which are based on physical flow in transmission lines, line flow matrix, power flow topology, complex power flow tracing, power flow tracing considering loop flows, separation of transmission losses [56-65]. In 2011, Nikoukar et al. [66] explained the transmission expansion pricing based on proportional tree method and economic benefit method.

\section{Power Flow Tracing Techniques Based on Circuit Theory}

In Feb 1999, Yang and Anderson [67] proposed a power flow comparison method for power flow tracing and compare this method with the existing methods. In Feb 2001, Liu et al. $[68,69]$ proved and extended the proportional sharing rule by network theory and graph theorem. In [69] based on the [68] proportional Sharing principle is incorporated with the load-flow tracing method. In Nov 2001, Reta and Vargas [70] explained a new method for power flow tracing based on the concept of electric circuit theory in which the influence areas are determined. In March 2002, Peng and Jiang $[71,72]$ explained a method of power flow tracing based on the definitions and concepts of total differential and the definite integral. In [72], Peng and Jiang proposed a principle to trace the complex power flow and the theory proposed in [71] is applied to element's equivalent circuits to obtain a nonlinear relationship between the complex power components flowing into and out of an element from a power source. In 2002, Chang and Lu [73] explained a node based strategy for tracing the current and power flows in a network. In December 2004, Teng [74] explained method based on the basic circuit theories, equivalent current injection and equivalent impedance to allocate the power flow and loss for deregulated transmission systems. In April 2006, Lin et al. [75] explained a method to trace the power flow based on the converged AC power flow solution. In December 2007, Sulaiman et al. [76] explained the power flow tracing method based on converged load flow, basic circuit theories including superposition theory, equivalent impedance and equivalent current injection. In June 2007, Meng and Jeyasurya [77] explained a simple transmission pricing scheme using a power flow tracing method, which incorporated transmission service cost, congestion cost and loss cost. In Nov 2009, Mohammadi et al. [78] explained an approach based on actual operation of the power network and using a conversion of load model, superposition principle. In March 2011, Qu et al. [79] explained a method of power flow tracing which is based on the concept of the power supply path of source under the constraints of all the basic electrical laws.

4.1. Based on Z-Bus Tracing. In Feb 2001, Conejo et al. [80] proposed a transmission loss allocation method based on the Z-bus matrix. In Oct 2002, Zhaoxia et al. [81] explained an expression-analysis based power allocation method for transmission loss allocation in which Generators (loads) are replaced with current sources while loads (generators) are replaced with shunt branches. In September 2004, Zhao et al. [82] explained a redistribution loss allocation method for improving Z-Bus loss allocation. On March 2005, Daniel et wal. [83] proposed a method to allocate the active power transmission loss which is based on the inclusion of the admittances equivalent to bus power injections in the bus admittance matrix. In November 2006, Kazemi and Andami [84] explained the multi-area power system transmission loss allocation based on the $\mathrm{Z}$ bus matrix. In February 2007, Conejo et al. [85] explained a method of network cost allocation based on Z-bus matrix. In November 2008, Lalitha and Sydulu [86] explained a direct transmission network cost allocation method by finding the coefficients of real and reactive power generations and load demands in the complex line flow. From 2008 to 2010, Parastar et al. proposed a method to allocate the transmission loss based on the basic circuit theories, equivalent current injection and modified Z-Bus [87, 88]. In December 2008, Mustafa et al. [89] explained a new method to identify the real power transfer between generators and load using modified nodal equations. In December 2008, Chen and Chu [90] explained the redistribution of Z-bus loss allocation for finding the contribution/attribution of the current flow between generation and load. In 2008, Shareef et al. [91] explained a method to identify the real and reactive power transfer between generators and load using modified nodal equations. In Sept 2010, Kilyeni et al. [92] explained a transmission cost allocation method, using the real and reactive power flow tracing which is based on the Z-bus system matrix.

\section{Power Flow Tracing Based on Optimization Techniques}

In Nov 2003, Conejo et al. [93] explained a procedure for the allocation of the transmission loss cost that is based on deriving a radial network. This equivalent network is derived solving a simple quadratic optimization problem. In Nov 2005, Vlachogiannis and Lee [94] explained a method that determined generator contributions to the transmission system by an evolutionary computation technique. From 2005 to 2007, Abhyankar et al. proposed various paradigms of MW power tracing algorithms and real power flow tracing. They also explained tracing compliant modified postage stamp method and transmission service charge based real power flow tracing method. Same authors furnished power flow tracing methods based on optimization approach and min-max 
fairness criteria [95-102]. In Dec 2008, Amoli and Jadid [103] used a proportional tracing and optimal real power tracing method for allocation of loss. From 2009 to 2011, Hamid et al. proposed methods for allocating the losses and generated power by means of Evolutionary Programming (EP) algorithm [104, 105]. In Aug 2010, Rao et al. [106] explained the Min-Max fair allocation criteria for transmission system usage allocation. In Dec 2010, Basak et al. [107] explained a modification in the existing pool based nodal charging technique by accommodating the bilateral transactions also which is done by posing the problem of creating virtual exchanges as an optimization problem.

\section{Power Flow Tracing Based on the Relative Electrical Distance Concept}

Consider a system where $n$ is the total number of buses with $1,2, \ldots, g, g$ is number of generator buses, and $g+1 \cdots n$, remaining $(n-g)$ load buses. For a given system we can write,

$$
\left[\begin{array}{c}
I_{G} \\
I_{L}
\end{array}\right]=\left[\begin{array}{cc}
Y_{G G} & Y_{G L} \\
Y_{L G} & Y_{L L}
\end{array}\right]\left[\begin{array}{c}
V_{G} \\
V_{L}
\end{array}\right],
$$

where $I_{G}, I_{L}$ and $V_{G}, V_{L}$ represent complex current and voltage vectors at the generators nodes and load nodes.

$\left[Y_{G G}\right],\left[Y_{G L}\right],\left[Y_{L L}\right]$, and $\left[Y_{L G}\right]$ are corresponding partitioned portions of network $Y$-bus matrix. Rearranging the equation we get,

$$
\left[\begin{array}{c}
V_{L} \\
I_{G}
\end{array}\right]=\left[\begin{array}{ll}
Z_{L L} & F_{L G} \\
K_{G L} & Y_{G G}
\end{array}\right]\left[\begin{array}{c}
I_{L} \\
V_{G}
\end{array}\right],
$$

where $\left[F_{L G}\right]=-\left[Y_{L L}\right]^{-1}\left[Y_{L G}\right]$. This matrix gives the relation between load bus voltages and source bus voltages. It also gives information about the location of load nodes with respect to generator nodes that is termed as relative electrical distance (RED) between load nodes and generator nodes.

The relative electrical distances, that is, the relative locations of load nodes with respect to the generator nodes are obtained from the $\left[F_{L G}\right]$ matrix and is given by (10)

$$
\left[R_{L G}\right]=1-\operatorname{abs}\left\{\left[F_{L G}\right]\right\} \text {. }
$$

The desired proportions of generation for the desired load sharing/generation scheduling are also obtained from the $\left[F_{L G}\right]$ matrix and is given by

$$
\left[D_{L G}\right]=\operatorname{abs}\left\{\left[F_{L G}\right]\right\} \text {. }
$$

In 2003, Visakha et al. proposed a method of transmission charge allocation based on the RED concept $[108,109]$. In 2008-2009, Thukaram et al. proposed and explained power flow tracing and transmission loss charge allocation methods based on a RED concept. They also furnished a T-index which is used for ranking new generation expansion locations [110112].

\section{Power Flow Tracing Based on Cooperative Game Theory}

In May 1996, Tsukamoto and Iyodo [113] described a methodology to allocate the cost of transmission network facilities. It is based on the combination of MW-Mile method with cooperative game theory. Kattuman et al. [114] presented a tracing technique for pricing inter-area electricity trades. In Aug 1999, Yeung and Poon [115] explained a multi agent model in conjunction with game theory to resolve the coalition formation in multilateral trades. In Oct 2000, Yu et al. [116] presented a method for transmission line embedded cost allocation using cooperative game theory. They also presented a comparison between the methods of transmission embedded cost allocation [117]. In Jan 2002, Tan and Lie [118] applied Shapley value of cooperative game theory for allocation of transmission cost to loads and generators. In May 2002 Yu et al. [119] proposed transmission line embedded cost allocated method accounting line capacity use and reliability benefits. In Nov 2002, Zolezzi and Rudnick [120] explained cooperative game theory based transmission cost allocation method. In this work cooperative game theory solution such as Shapley value and nucleolus are compared with conventional methods. In May 2004, Stamtsis and Erlich [121] implemented the game theory solutions such as Shapley value and Nucleolus for the power system fixed cost allocation in the pool and bilateral market. In March 2005, Bjorndal et al. [122] presented a method for computing the nucleolus of a cooperative game, by which several usage-based methods may be combined to produce allocations that are in, or as close as possible to, the core. In Nov 2007, Junqueira et al. [123] presented a methodology based on the Aumann-Shapley scheme for energy transmission costs allocation between network users in energy markets. In Dec 2008, Bhakar et al. [124] provided a game theoretic model that allocates the transmission and distribution network costs based on Nucleolus and Shapley Value approaches. In 2009, Bhakar et al. [125] proposed a variety of probabilistic cooperative game theory approaches. In June 2003, Juan Zolezzi and Rudnick [126] proposed a transmission cost allocation method, based on cooperative game theory and transmission network capacity use of consumer agents. Singh et al. [127] dealt with the problem of allocating common costs in electric power networks using principles from cooperative game theory. In 2011 Balagopalan and Anooja [128] applied cooperative game theory for sharing transmission charges in electricity markets.

\section{Equilateral Bilateral Exchange}

The term equivalent bilateral exchange represents a power injection and an offtake of the same entity. It suggests the existence of a generator and a demand with the same real power, but in opposite directions. Assuming a generator $P_{g}$ at bus $i$ and a demand $P_{d}$ at bus $j$, the bilateral exchange between generator and demand is given by

$$
G D_{i j}=\frac{P_{g i} P_{d j}}{P_{d}^{\mathrm{sys}}},
$$

where in a lossless network, the system demand $P_{d}^{\text {sys }}=$ $\sum_{j} P_{d j}=\sum_{i} P_{g i}$.

The equivalent exchange $G D_{i j}$ can be viewed as the fraction of the generation $P_{g i}$ that supplies the bus demand $P_{d j}$, or equivalently the fraction of demand $P_{d j}$ supplied by the generation $P_{g i}$. 
To decompose each individual generation and demand level into linear combinations of the equivalent bilateral exchanges (13) is used

$$
\begin{aligned}
& P_{g i}=\sum_{i} G D_{i j}, \\
& P_{d j}=\sum_{j} G D_{i j} .
\end{aligned}
$$

The net flow in an arbitrary line $k$ can be therefore be expressed uniquely in terms of the equivalent bilateral exchanges as

$$
P_{f k}=\sum_{i-j} \gamma_{i j k} G D_{i j}
$$

The use of line $k$ by generation $P_{g i}$ and load $P_{d j}$ can be determined by the following expressions:

$$
\begin{aligned}
& U G_{i k}=\sum_{j}\left|\gamma_{i j k}\right| G D_{i j}, \\
& U D_{j k}=\sum_{i}\left|\gamma_{i j k}\right| G D_{i j},
\end{aligned}
$$

where $\gamma_{i j k}$ is a generation shift factor through network element $k$, corresponding to changes in generator at bus $i$.

In Nov 2003, Galiana et al. [129] present a methodology for allocating the cost of a transmission network to its users based on the principle of equivalent bilateral exchanges. In Oct 2005, Silva et al. [130] presented a new strategy designed with the purpose of achieving revenue adequacy in congested networks that use financial transmission rights (FTR) markets. In 2008, [131] same authors presented a new strategy based on the principle of equivalent bilateral exchanges for the allocation of costs related to electric network congestion management. In Nov 2005, Mateus and Franco [132] presented a new loss allocation scheme based on equivalent bilateral exchanges. In Dec 2008, Nouri and Jadid [133] proposed a loss allocation method based on equivalent bilateral exchanges and genetic algorithm.

\section{Case Studies}

Case studies presented the suitability and practicability of various methods to be implemented on practical systems. This section deals with those publications, which are related to restructuring or deregulation experience in different countries.

In April 2000, Bialek [8] applied tracing-based unified framework for transmission pricing of cross-border trades in the European interconnected network. In August 2002, Limpasuwan et al. [13] implemented tracing methodology on Electricity Generating Authority of Thailand (EGAT) system. In June 2006, Thukaram et al. [27] presented a case study on an equivalent 11-bus system, a part of Indian Southern Grid, based on the concepts of circuit flow directions. In 2004, Pantoš and Gubina [33] presented an Ex-ante transmissionservice pricing via power-flow tracing on 194 nodes Slovenian power system. In April 2000, Xi-Fan et al. [38] presented a power tracing analysis on UK 30 node system. In August 2008, Lim et al. [52] applied loop based tracing method on modified CIGRE Nordic32 bus system. In December 2008, Mustafa et al. [89] implemented a new method of real power flow tracing on practical 25 bus equivalent power system of south Malaysia. In 2005, Abhyankar et al. [97] implemented a power flow tracing algorithm on a Western regional grid of India. In [100] Abhyankar et al. Applied optimization approach in power flow tracing on a Western regional grid of India. In November 2007, Junqueira et al. [123] implemented a transmission cost allocation method based on the Aumann Shapley approach of game theory on the Brazilian power system. In June 2003, Zolezzi and Rudnick [126] proposed a method based on cooperative game theory and transmission network capacity use. They implemented the proposed method on the main Chilean interconnected system.

\section{Discussion}

A review of various methods based on power flow tracing is presented. Tracing based on proportional sharing principle is very simple and easy to understand. But it does not provide efficient economic signals. Also it is not based on any fairness criteria. Hence it has some degree of arbitrariness [2].

Optimization approach is most suitable for large power system [106]. But it is complex and time consuming. The objective function is formed which is optimized and gives optimum results.

In the game theory the participants make rational decisions in a conflicting competitive solution. This approach gives efficient economic signals. It is most suitable for the present competitive scenario. But its applicability is limited to large power system due to cumbersome calculation [118].

Equilateral bilateral exchange (EBE) is a reasonable way to determine the combination of each generator to each demand. The main advantage of this method is its independence on selection of slack bus. In this method slack bus is created for each EBE. But EBE is a purely mathematical concept which does not exist in reality. But by this way we can observe all the different configurations of generator demand [129].

Circuit theory based methods depends on exact network equation which is defined by the complex impedance matrix. All the calculations based on the sparse admittance matrix. These methods are easy to formulate [85].

Graph theory is widely used for allocation of transmission usage to loads and generators. Various matrixes such as incidence matrix, adjacency matrix are used for tracing purpose. These methods are simple and easy to implement. But this methodology also follows the proportional sharing principle [1].

Relative electrical distance method allocates the transmission charges based on the relative location of the load node with respect to generator node. It is simple and can be implemented using the network configuration and generation/load conditions. It does not require performing load flow analysis whenever each contract/transaction is exercised. The main advantage of the developed method lies in its applicability to consider multiple contracts/transactions simultaneously [109]. 


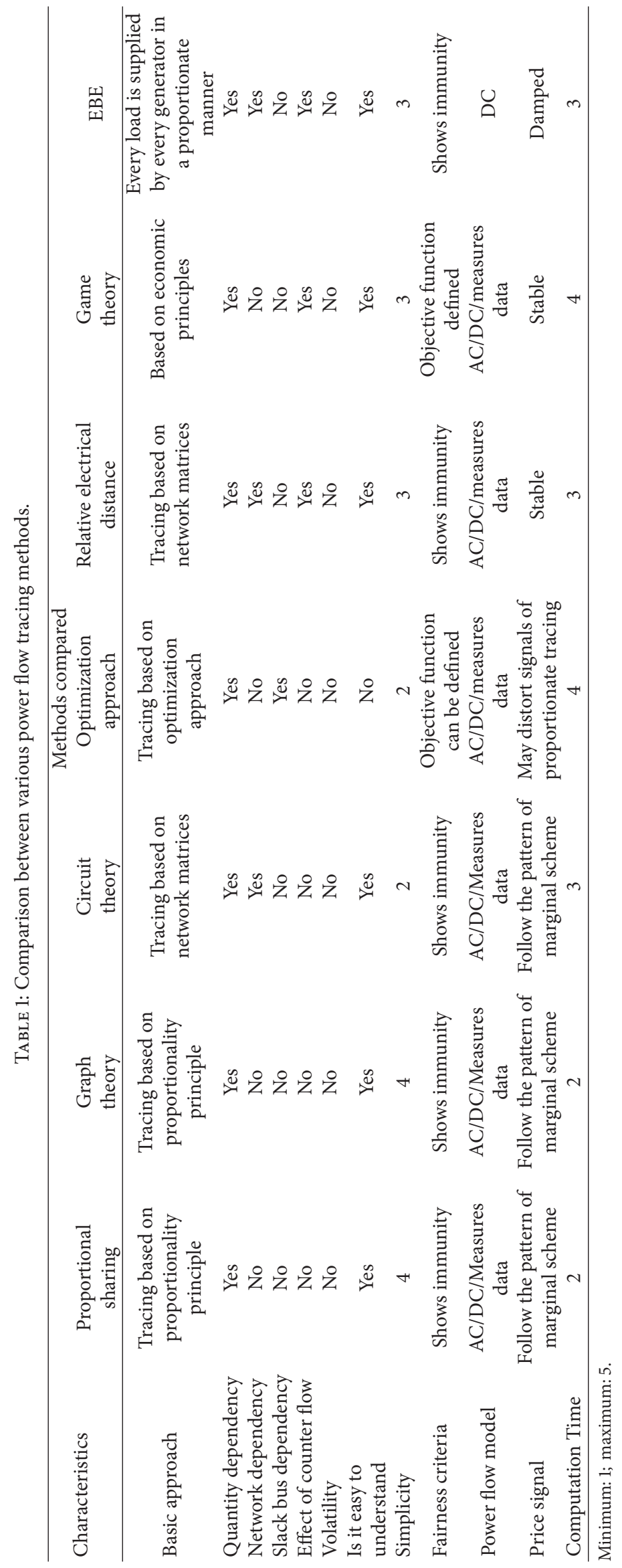


A comparison between various power flow tracing methodologies is presented Table 1.

\section{Conclusion}

This paper presents an overview of transmission pricing methods based on or using power flow tracing techniques in a deregulated environment of the power system. The main principle used in power flow tracing is the proportional sharing principle which is based on the Kirchhoff's current law. The other approaches are based on graph theory, circuit theory, optimization techniques, Z-bus matrix, relative electrical distance, and EBE. This paper makes overall, systematic summary and analysis of the existing allocation methods which are classified according to different tracing techniques.

\section{Conflict of Interests}

The authors declare that there is no conflict of interests regarding the publication of this paper.

\section{References}

[1] K. Xie, J. Zhou, and W. Li, "Analytical model and algorithm for tracing active power flow based on extended incidence matrix," Electric Power Systems Research, vol. 79, no. 2, pp. 399-405, 2009.

[2] J. Bialek, "Tracing the flow of electricity," IEE Proceedings-Generation, Transmission and Distribution, vol. 143, no. 4, pp. 313320, 1996.

[3] J. Bialek and D. B. Tam, "Tracing the generators' output," in Proceedings of the International Conference on Opportunities and Advances in International Electric Power Generation, pp. 133136, Durham, NC, USA, March 1996.

[4] J. Bialek, "Identification of source-sink connections in transmission networks," in Proceedings of the 4th International Conference on Power System Control and Management, pp. 200-204, April 1996.

[5] J. Bialek, "Topological generation and load distribution factors for supplement charge allocation in transmission open access," IEEE Transactions on Power Systems, vol. 12, no. 3, pp. 1185-1193, 1997.

[6] J. Bialek, "Allocation of transmission supplementary charge to real and reactive loads," IEEE Transactions on Power Systems, vol. 13, no. 3, pp. 749-754, 1998.

[7] P. A. Kattuman, J. W. Bialek, and N. Abi-Samra, "Electricity tracing and co-operative game theory," in Proceedings of the 13th Power System Computation Conference, pp. 238-243, Trondheim, Norway, June 1999.

[8] J. W. Bialek, "Tracing-based unifying framework for transmission pricing of cross-border trades in Europe," in Proceedings of the International Conference on Electric Utility Deregulation and Restructuring and Power Technologies (DRPT '00), pp. 532-537, London, UK, April 2000.

[9] J. W. Bialek, S. Ziemianek, and R. Wallace, "A methodology for allocating transmission losses due to cross-border trades," IEEE Transactions on Power Systems, vol. 19, no. 3, pp. 1255-1262, 2004.

[10] Y. Z. Li, S. H. Zhang, Q. Liu, and Z. Qu, "Electricity tracing method of generation and loss cost allocation," in Proceedings of the 5th International Conference on Advances in Power System Control, Operation and Management (APSCOM '00), Hong Kong, China, October 2000.

[11] C. T. Su and J. H. Liaw, "Power wheeling pricing using power tracing and MVA-KM method," in Proceedings of the IEEE Porto Power Tech, vol. 1, Porto, Portugal, September 2001.

[12] A. N. Al-Rajhi and J. W. Bialek, "Marginal and tracing pricing of transmission: an empirical comparison," in Proceedings of the 14th Power Systems Computation Conference, session 27, paper 5, Sevilla, Spain, June 2002.

[13] T. Limpasuwan, J. W. Bialek, W. Ongsakul, and B. Limmeechokchai, "A proposal for annual power fee in Thailand based on electricity tracing methodology," Electric Power Systems Research, vol. 64, no. 3, pp. 219-226, 2003.

[14] J. W. Bialek, "Gaming the uniform-price spot market: quantitative analysis," IEEE Transactions on Power Systems, vol. 17, no. 3, pp. 768-773, 2002.

[15] A. R. Shirani and H. Siahkali, "Traceable flow method in determination of congestion cost assignment in open access power system network," in Proceedings of the IEEE/PES Transmission and Distribution Conference and Exhibition 2002: Asia Pacific, vol. 2, pp. 734-738, October 2002.

[16] T. Limpasuwan, J. W. Bialek, W. Ongsakul, and B. Limmeechokchai, "A proposal for transmission pricing methodology in Thailand based on electricity tracing and long-run average incremental cost," Energy Policy, vol. 32, no. 3, pp. 301-308, 2004.

[17] P. A. Kattuman, R. J. Green, and J. W. Bialek, "Allocating electricity transmission costs through tracing: a game-theoretic rationale," Operations Research Letters, vol. 32, no. 2, pp. 114-120, 2004.

[18] J. W. Bialek and S. Ziemianek, "Tracing based transmission pricing of cross-border trades: fundamentals and circular flows," in Proceedings of the IEEE Bologna Power Tech Conference, vol. 3, Bologna, Italy, June 2003.

[19] J. W. Bialek and P. A. Kattuman, "Proportional sharing assumption in tracing methodology," IEE Proceedings-Generation, Transmission and Distribution, vol. 151, no. 4, pp. 526-532, 2004.

[20] C. Adsoongnoen, W. Ongsakul, and H. J. Haubrich, "Allocation of transmission losses and network charges for cross border trades in ASEAN power grid based on tracing methodology," in Proceedings of the IEEE Russia Power Tech, pp. 1-6, St. Petersburg, Russia, June 2005.

[21] P. Nallagownden, R. N. Mukerjee, and S. Masri, "Power tracing and prediction of losses for deregulated transmission system," International Journal of Electrical and Computer Sciences, vol. 10, no. 1 .

[22] K. Pal, M. Pandit, and L. Srivastava, "Incentive charge calculation for open access transmission system," in Proceedings of the International Conference on Power Systems (ICPS '09), pp. 1-6, Kharagpur, India, December 2009.

[23] C. Achayuthakan, C. J. Dent, J. W. Bialek, and W. Ongsakul, "Electricity tracing in systems with and without circulating flows: physical insights and mathematical proofs," IEEE Transactions on Power Systems, vol. 25, no. 2, pp. 1078-1087, 2010.

[24] P. Nallagownden and T. Y. Lee, "Application of regression and tracing methodology for efficient operation of generators and retailers in a deregulated system," in Proceedings of the 4th International Power Engineering and Optimization Conference (PEOCO '10), pp. 267-273, Selangor, Malaysia, June 2010.

[25] B. Naresh, M. S. Kumari, and M. Sydulu, "Transmission cost allocation using power flow tracing and genetic algorithm," in Proceedings of the 5th IEEE International Conference on Intelligent Systems (IS '10), pp. 432-438, London, UK, July 2010. 
[26] D. K. Ron and A. G. Strbac, "Contributions of individual generators to loads and flows," IEEE Transactions on Power Systems, vol. 12, no. 1, pp. 52-60, 1997.

[27] D. Thukaram, H. P. Khincha, B. Ravikumar, and G. Yesuratnam, "Generators contribution towards loads and line flows-a case study," in Proceedings of the IEEE Power India Conference, New Delhi, India, April 2006.

[28] G. Strbac, D. Kirschen, and S. Ahmed, "Allocating transmission system usage on the basis of traceable contributions of generators and loads to flows," IEEE Transactions on Power Systems, vol. 13, no. 2, pp. 527-534, 1998.

[29] D. Kirschen and G. Strbac, "Tracing active and reactive power between generators and loads using real and imaginary currents," IEEE Transactions on Power Systems, vol. 14, no. 4, pp. 1312-1319, 1999.

[30] F. Gubina and D. Orgie, "A method for determining the generators' share in a consumer load," IEEE Transactions on Power Systems, vol. 15, no. 4, pp. 1376-1381, 2000.

[31] D. Grgic and F. Gubina, "Generator contribution to a line reactive power flow," in Proceedings of the International Conference on Power System Technology (PowerCon '00), vol. 3, pp. 15871590, Perth, Wash, USA, 2000.

[32] M. Pantos, D. Grgic, and F. Gubina, "New transmission service pricing technique based on actual power flows," in Proceedings of the IEEE Bologna Power Tech Conference, vol. 3, Bologna, Italy, June 2003.

[33] M. Pantoš and F. Gubina, "Ex-ante transmission-service pricing via power-flow tracing," International Journal of Electrical Power and Energy System, vol. 26, no. 7, pp. 509-518, 2004.

[34] M. Pantoš and F. Gubina, "Ex-ante transmission service pricing via load distribution factors," in Proceedings of the IEEE Power Engineering Society General Meeting, vol. 2, p. 4, July 2003.

[35] M. Pantos and F. Gubina, "Allocation of production to consumers," in Proceedings of the IEEE EUROCON, vol. 2, pp. 301304, September 2003.

[36] M. Pantoš and F. Gubina, "Ex-ante transmission-service pricing based on load-flow patterns," IEEE Transactions on Power Systems, vol. 19, no. 2, pp. 796-801, 2004.

[37] H. Sun, D. C. Yu, and Q. Zheng, "AC power flow tracing in transmission networks," in Proceedings of the IEEE Power Engineering Society Winter Meeting, vol. 3, pp. 1715-1720, January 2000.

[38] W. Xi-Fan, W. Xin-Li, and J. Bin, "Power tracing analysis in wheeling costing," in Proceedings of the International Conference on Electric Utility Deregulation and Restructuring and Power Technologies (DRPT '00), pp. 173-178, London, UK, 2000.

[39] P. Wei, B. Yuan, Y. Ni, and F. F. Wu, "Power flow tracing for transmission open access," in Proceedings of the International Conference on Electric Utility Deregulation and Restructuring and Power Technologies (DRPT '00), pp. 476-481, London, UK, 2000.

[40] F. F. Wu, Y. Ni, and P. Wei, "Power transfer allocation for open access using graph theory-fundamentals and applications in systems without loopflow," IEEE Transactions on Power Systems, vol. 15, no. 3, pp. 923-929, 2000.

[41] S. K. Chai and A. Sekar, "Graph theory application to deregulated power system," in Proceedings of the 33rd Southeastern Symposium on System Theory, pp. 117-121, Athens, Ohio, USA, March 2001.

[42] P. Wei, Y. Ni, and F. F. Wu, "Load flow tracing in power systems with circulating power," International Journal of Electrical Power and Energy Systems, vol. 24, no. 10, pp. 807-813, 2002.
[43] K. Xie and J. Zhou, "Power flow tracing algorithm for electric networks with loopflow," Science in China E, vol. 46, no. 1, pp. 93-103, 2003.

[44] K. Xie, C. Li, and Y. Liu, "Tracing power flow from generators to loads and branches using incidence matrix multiplication," in Proceedings of the IEEE Power and Energy Society General Meeting (PES '09), pp. 1-7, Calgary, Canada, July 2009.

[45] H. Ghasemi, C. Cañizares, and G. Savage, "Closed-form solution to calculate generator contributions to loads and line flows in an open access market," in Proceedings of the IEEE Power Engineering Society General Meeting, vol. 2, July 2003.

[46] M. W. B. Mustafa and H. Shareef, "An alternative power tracing method for transmission open access," http://itee.uq.edu.au/ aupec/aupec05/AUPEC2005/Volume1/S091.pdf.

[47] M. W. Mustafa and M. H. Sulaiman, "Transmission loss allocation in deregulated power system via superposition and proportional tree methods," in Proceedings of the 2nd IEEE International Power and Energy Conference (PECon '08), pp. 988-993, Johor Baharu, Malaysia, December 2008.

[48] M. W. Mustafa, M. H. Sulaiman, H. Shareef, and S. N. Abd Khalid, "Determination of generators' contributions to loads in pool based power system using least squares support vector machine," in Proceedings of the 4th International Power Engineering and Optimization Conference (PEOCO '10), pp. 226-231, Selangor, Malaysia, June 2010.

[49] Y. Xiao and P. Wang, "Tracing nodal market power using proportional tree method," in Proceedings of the IEEE PES Power Systems Conference and Exposition, vol. 1, pp. 196-200, October 2004.

[50] P. Wang and Y. Xiao, "Transmission cost allocation using proportional tree methods," in Proceedings of the 7th International Power Engineering Conference (IPEC '05), pp. 1-126, Singapore, December 2005.

[51] V. S. C. Lim, J. D. F. McDonald, and T. K. Saha, "Application of loop frame of reference to power flow tracing and loss allocation," in Proceedings of the 7th International Power Engineering Conference (IPEC '05), vol. 2, pp. 1013-1018, Singapore, December 2005.

[52] V. S. C. Lim, J. D. F. McDonald, and T. K. Saha, "Development of a new loss allocation method for a hybrid electricity market using graph theory," Electric Power Systems Research, vol. 79, no. 2, pp. 301-310, 2009.

[53] V. S. C. Lim, J. D. F. McDonald, and T. K. Saha, "Application of loop frame of reference to power flow tracing and loss allocation," International Journal of Emerging Electric Power Systems, vol. 5, no. 2, article 3, 2006.

[54] C. T. Su, J. H. Liaw, and C. M. Li, "Power-flow tracing and wheeling costing considering complex power and convection lines," IEE Proceedings-Generation, Transmission and Distribution, vol. 153, no. 1, pp. 1-10, 2006.

[55] C. T. Su and J. H. Liaw, "Complex power flow tracing considering convection lines using nominal-T model," International Journal of Electrical Power and Energy Systems, vol. 29, no. 1, pp. 28-35, 2007.

[56] S. Abdelkader, "Transmission loss allocation in a deregulated electrical energy market," Electric Power Systems Research, vol. 76, no. 11, pp. 962-967, 2006.

[57] S. Abdelkader, "Allocating generation to loads and line flows for transmission open access," in Proceedings of the IEEE GCC Conference, pp. 1-6, Manama, Bahrain, March 2006. 
[58] S. Abdelkader, "Efficient computation algorithm for calculating load contributions to line flows and losses," IEE ProceedingsGeneration, Transmission and Distribution, vol. 153, no. 4, pp. 391-398, 2006.

[59] S. M. Abdelkader, "Transmission loss allocation through complex power flow tracing," in Proceedings of the 11th International Middle East Power Systems Conference (MEPCON '2006), vol. 1, pp. 310-316, Minya, Egypt, December 2006.

[60] S. Abdelkader, "A method for determining generators' shares in loads, line flows and losses," Journal of the Franklin Institute, vol. 344, no. 8, pp. 1063-1074, 2007.

[61] S. M. Abdelkader, "Allocating transmission loss to loads and generators through complex power flow tracing," IET Generation, Transmission and Distribution, vol. 1, no. 4, pp. 584-595, 2007.

[62] S. M. Abdelkader, "Transmission loss allocation through complex power flow tacing," IEEE Transactions on Power Systems, vol. 22, no. 4, pp. 2240-2248, 2007.

[63] S. Abdelkader, "Determining generators' contribution to loads and line flows \& losses considering loop flows," International Journal of Electrical Power and Energy Systems, vol. 30, no. 6-7, pp. 368-375, 2008.

[64] S. M. Abdelkader, "A new method for transmission loss allocation considering the circulating currents between generators," in Proceedings of the 12th International Middle East Power System Conference (MEPCON '08), pp. 282-286, Aswan, Egypt, March 2008.

[65] S. M. Abdelkader, "Complex power flow tracing for transmission loss allocation considering loop flows," in Proceedings of the IEEE Power and Energy Society General Meeting (PES '09), pp. 1-9, Calgary, Canada, July 2009.

[66] J. Nikoukar, M. R. Haghifam, and A. Panahi, "Transmission expansion cost allocation based on economic benefit and use of system," Journal of American Science, vol. 7, no. 4, 2011.

[67] J. Yang and M. D. Anderson, "Tracing the flow of power in transmission networks for use-of-transmission-system charges and congestion management," in Proceedings of the Winter Meeting of IEEE Power Engineering Society, vol. 1, pp. 399-405, February 1999.

[68] F. Liu, Y. Li, and G. Tang, "A quick and practicable power flow tracing method on electric energy market part I: theoretic fundament," in Proceedings of the IEEE Power Engineering Society Winter Meeting, vol. 3, pp. 1244-1249, Columbus, Ohio, USA, February 2001.

[69] F. Liu, Y. Li, and G. Tang, "A quick and practicable power flow tracing method on electric energy market part II: a new practicable method," in Proceedings of the IEEE Power Engineering Society Winter Meeting, vol. 3, pp. 1238-1243, Columbus, Ohio, USA, February 2001.

[70] R. Reta and A. Vargas, "Electricity tracing and loss allocation methods based on electric concepts," IEE Proceedings-Generation, Transmission and Distribution, vol. 148, no. 6, pp. 518-522, 2001.

[71] J. C. Peng and H. Jiang, "Contributions of individual generators to complex power losses and flows-part 1: fundamental theory," IEE Proceedings-Generation, Transmission and Distribution, vol. 149, no. 2, pp. 182-185, 2002.

[72] J. C. Peng and H. Jiang, "Contributions of individual generators to complex power losses and flows-part 2: algorithm and simulations," IEE Proceedings-Generation, Transmission and Distribution, vol. 149, no. 2, pp. 186-190, 2002.
[73] Y. C. Chang and C. N. Lu, "Electricity tracing method with application to power loss allocation," International Journal of Electrical Power and Energy System, vol. 23, no. 1, pp. 13-17, 2001.

[74] J. H. Teng, "Power flow and loss allocation for deregulated transmission systems," International Journal of Electrical Power and Energy Systems, vol. 27, no. 4, pp. 327-333, 2005.

[75] W. M. Lin, T. S. Zhan, and C. H. Huang, "A circuit theory based load flow tracing method considering counter-flow contribution," in Proceedings of the 5th WSEAS International Conference on Instrumentation, Measurement, Circuits and Systems (IMCAS '06 ), pp. 312-317, Hangzhou, China, April 2006.

[76] M. H. Sulaiman, O. Aliman, M. W. Mustafa, and I. Daut, "Tracing generators' output in transmission open access," in Proceedings of the 5th Student Conference on Research and Development (SCORED '07), pp. 1-6, Selangor, Malaysia, December 2007.

[77] Y. Meng and B. Jeyasurya, "Investigation of transmission cost allocation using a power flow tracing method," in Proceedings of the IEEE Power Engineering Society General Meeting, pp. 1-7, Tampa, Fla, USA, June 2007.

[78] M. Mohammadi, A. Ebrahimi, and T. Daemi, "Accurate determination of active power transmission paths for contribution allocation of generating units," in Proceedings of the International Conference on Electric Power and Energy Conversion Systems (EPECS '09), pp. 1-5, November 2009.

[79] Z. J. Qu, J. H. Qin, X. T. Wang, H. Bao, and C. Zhou, "A power flow tracing method based on the circuit analysis of power supply path," in Proceedings of the Asia-Pacific Power and Energy Engineering Conference (APPEEC '11), pp. 1-6, Wuhan, China, March 2011.

[80] A. J. Conejo, F. D. Galiana, and I. Kockar, "Z-bus loss allocation," IEEE Transactions on Power Systems, vol. 16, no. 1, pp. 105-110, 2001.

[81] J. Zhaoxia, D. Xianzhong, and H. Yangzan, "A new expressionanalysis-based losses allocation method," in Proceedings of the IEEE/PES Transmission and Distribution Conference and Exhibition 2002: Asia Pacific, vol. 3, pp. 1982-1985, October 2002.

[82] N. Zhao, Y. H. Song, Z. H. Bie, S. Takahash, and Y. Sekine, "Improved Z-bus loss allocation method through redistribution," in Proceedings of the 39th International Universities Power Engineering Conference (UPEC '04), vol. 3, pp. 1101-1105, September 2004.

[83] J. S. Daniel, R. S. Salgado, and M. R. Irving, “Transmission dloss allocation through a modified Y-Bus," IEE Proceedings-Generation, Transmission and Distribution, vol. 152, no. 2, pp. 208-214, 2005.

[84] A. Kazemi and H. Andami, "Multi-area power system loss allocation using Z-bus method," in Proceedings of the 1st International Power and Energy Conference (PECon '06), pp. 286-291, Putra Jaya, Malaysia, November 2006.

[85] A. J. Conejo, J. Contreras, D. A. Lima, and A. Padilha-Feltrin, "Zbus transmission network cost allocation," IEEE Transactions on Power Systems, vol. 22, no. 1, pp. 342-349, 2007.

[86] S. V. N. L. Lalitha and M. Sydulu, "A direct method for transmission network cost allocation," in Proceedings of the IEEE TENCON Region 10 Conference, pp. 1-6, Hyderabad, India, November 2008 .

[87] A. Parastar, A. Pirayesh, B. Mozafari, B. Khaki, R. Sirjani, and A. Mehrtash, "A new method for power loss allocation by modified Y-Bus matrix," in Proceedings of the IEEE International Conference on Sustainable Energy Technologies (ICSET '08), pp. 11841188, Singapore, November 2008. 
[88] A. Parastar, B. Mozafari, A. Pirayesh, and H. Omidi, "Transmission loss allocation through modified Z-bus," Energy Conversion and Management, vol. 52, no. 1, pp. 752-756, 2011.

[89] M. W. Mustafa, S. N. Khalid, H. Shareef, and A. Khairuddin, "A new method for real power transfer allocation using modified nodal equations," in Proceedings of the 2nd IEEE International Power and Energy Conference (PECon '08), pp. 1306-1310, Johor Baharu, Malaysia, December 2008.

[90] Y. P. Chen and W. C. Chu, "Redistribution of transmission loss based on z-bus method," in Proceedings of the 2nd IEEE International Power and Energy Conference (PECon '08), pp. 10161020, Johor Baharu, Malaysia, December 2008.

[91] H. Shareef, M. W. Mustafa, S. Abd Khalid, A. Khairuddin, A. Kalam, and A. Maung Than Oo, "Real and reactive power transfer allocation utilizing modified Nodal equations," International Journal of Emerging Electric Power Systems, vol. 9, no. 6, article 4, 2008.

[92] S. Kilyeni, O. Pop, G. Prostean, and C. Craciun, "Transmission cost allocation based on power flow tracing using Z bus matrix," in Proceedings of the 14th International Conference on Harmonics and Quality of Power (ICHQP '10), pp. 1-6, Bergamo, Italy, September 2010.

[93] A. J. Conejo, N. Alguacil, and G. Fernández-Ruiz, "Allocation of the cost of transmission losses using a radial equivalent network," IEEE Transactions on Power Systems, vol. 18, no. 4, pp. 1353-1358, 2003.

[94] J. G. Vlachogiannis and K. Y. Lee, "Determining generator contributions to transmission system using parallel vector evaluated particle swarm optimization," IEEE Transactions on Power Systems, vol. 20, no. 4, pp. 1765-1774, 2005.

[95] A. R. Abhyankar, S. A. Soman, and S. A. Khaparde, "New paradigm of tracing algorithms: application to fair loss allocation in Indian system," in Proceedings of the International Conference on Future Power Systems, p. 6, November 2005.

[96] A. R. Abhyankar, S. A. Soman, and S. A. Khaparde, "Allocation of fixed transmission costs by tracing compliant postage stamp method," in Proceedings of the 7th International Power Engineering Conference (IPEC '05), pp. 1-132, Singapore, December 2005.

[97] A. R. Abhyankar, S. A. Khaparde, S. A. Soman, and P. Pentayya, "A transmission pricing mechanism based on power tracing for central transmission utility in India," International Journal of Emerging Electric Power Systems, vol. 2, no. 1, article 1033, 2005.

[98] A. R. Abhyankar, S. A. Soman, and S. A. Khaparde, "Real power tracing: an optimization approach," International Journal of Emerging Electric Power Systems, vol. 3, no. 2, article 1088, 2005.

[99] A. R. Abhyankar, S. A. Soman, and S. A. Khaparde, “Tractability of bilateral transactions considering multiplicity of solution space in real power tracing," in Proceedings of the IEEE Power India Conference, p. 8, New Delhi, India, April 2006.

[100] A. R. Abhyankar, S. A. Soman, and S. A. Khaparde, "Optimization approach to real power tracing: an application to transmission fixed cost allocation," IEEE Transactions on Power Systems, vol. 21, no. 3, pp. 1350-1361, 2006.

[101] A. R. Abhyankar, S. A. Khaparde, and S. A. Soman, "Multiple solutions approach to tackle circular flows in real power tracing," in Proceedings of the IEEE Power Engineering Society General Meeting, p. 8, June 2006.

[102] A. R. Abhyankar, S. A. Soman, and S. A. Khaparde, "Min-max fairness criteria for transmission fixed cost allocation," IEEE Transactions on Power Systems, vol. 22, no. 4, pp. 2094-2104, 2007.
[103] N. A. Amoli and S. Jadid, "Allocation of loss cost by optimal and proportional tracing methods," in Proceedings of the 2 nd IEEE International Power and Energy Conference (PECon '08), pp. 994-999, Johor Baharu, Malaysia, December 2008.

[104] Z. Hamid, I. Musirin, M. M. Othman, and N. A. Rahim, "Evolutionary programming based load tracing optimization in deregulated power system," http://www.wseas.us/e-library/conferences/2011/Meloneras/ACELAE/ACELAE-27.pdf.

[105] Z. A. Hamid, I. Musirin, M. M. Othman, and M. N. A. Rahim, "A novel technique for generation tracing via evolutionary programming," in Proceedings of the 5th International Power Engineering and Optimization Conference (PEOCO '11), pp. 381-386, Selangor, Malaysia, June 2011.

[106] M. S. S. Rao, S. A. Soman, P. Chitkara, R. K. Gajbhiye, N. Hemachandra, and B. L. Menezes, "Min-max fair power flow tracing for transmission system usage cost allocation: a large system perspective," IEEE Transactions on Power Systems, vol. 25, no. 3, pp. 1457-1468, 2010.

[107] A. Basak, S. Pal, A. R. Abhyankar, and B. K. Panigrahi, "Modified equivalent bilateral exchange of transmission pricing using DIWO," in Proceedings of the Joint International Conference on Power Electronics, Drives and Energy Systems (PEDES '10), pp. 1-6, New Delhi, India, December 2010.

[108] K. Visakha, D. Thukaram, L. Jenkins, H. P. Khincha, and P. K. Routray, "An approach for evaluation of transmisses charges based on desired and deviations of power contracts in open access," in Proceedings of the 6th International Conference on Advances in Power System Control, Operation and Management (APSCOM '03), pp. 860-866, Hong Kong, China, November 2003.

[109] K. Visakha, D. Thukaram, and L. Jenkins, "Transmission charges of power contracts based on relative electrical distances in open access," Electric Power Systems Research, vol. 70, no. 2, pp. 153-161, 2004.

[110] D. Thukaram and C. Vyjayanthi, "Ranking of prospective new generation location for a power network in a deregulated system," in Proceedings of the Joint International Conference on Power System Technology (POWERCON '08), pp. 1-8, New Delhi, India, October 2008.

[111] D. Thukaram and C. Vyjayanthi, "Evaluation of charges for power transmission and losses in bilateral power contracts," in Proceedings of the IEEE TENCON Region 10 Conference, pp. 1-6, Hyderabad, India, November 2008.

[112] D. Thukaram and C. Vyjayanthi, "Relative electrical distance concept for evaluation of network reactive power and loss contributions in a deregulated system," IET Generation, Transmission and Distribution, vol. 3, no. 11, pp. 1000-1019, 2009.

[113] Y. Tsukamoto and I. Iyoda, "Allocation of fixed transmission cost to wheeling transactions by cooperative game theory," in Proceedings of the IEEE Power Industry Computer Application Conference, pp. 3-10, May 1995.

[114] P. A. Kattuman, R. J. Green, and J. W. Bialek, "A tracing method for pricing inter area electricity trades," http://www.dspace.cam .ac.uk/bitstream/1810/286/1/wp0107.pdf.

[115] C. S. K. Yeung and A. S. Y. Poon, "Game theoretical multi-agent modelling of coalition formation for multilateral trades," IEEE Transactions on Power Systems, vol. 14, no. 3, pp. 929-934, 1999.

[116] C. W. Yu, A. K. David, and Y. K. Wong, "The use of game theory in transmission embedded cost allocation," in Proceedings of the International Conference on Advances in Power System Control, Operation and Management (APSCOM '00), vol. 1, pp. 139-143, October 2000. 
[117] C. W. Yu and Y. K. Wong, "Analysis of transmission embedded cost allocation scheme in open electricity market," Resource, Energy and Development, vol. 3, no. 1, pp. 1-11, 2006.

[118] X. Tan and T. T. Lie, "Application of the shapley value on transmission cost allocation in the competitive power market environment," IEE Proceedings-Generation, Transmission and Distribution, vol. 149, no. 1, pp. 15-20, 2002.

[119] C. W. Yu, A. K. David, C. T. Tse, and C. Y. Chung, "Capacityuse and reliability based transmission embedded cost allocation with temporal considerations," International Journal of Electrical Power and Energy Systems, vol. 25, no. 3, pp. 201-208, 2003.

[120] J. M. Zolezzi and H. Rudnick, "Transmission cost allocation by cooperative games and coalition formation," IEEE Transactions on Power Systems, vol. 17, no. 4, pp. 1008-1015, 2002.

[121] G. C. Stamtsis and I. Erlich, "Use of cooperative game theory in power system fixed-cost allocation," IEE ProceedingsGeneration, Transmission and Distribution, vol. 151, no. 3, pp. 401-406, 2004.

[122] E. Bjorndal, G. C. Stamtsis, and I. Erlich, "Finding core solutions for power system fixed cost allocation," IEE ProceedingsGeneration, Transmission and Distribution, vol. 152, no. 2, pp. 173-179, 2005.

[123] M. Junqueira, L. C. da Costa Jr., L. A. Barroso, G. C. Oliveira, L. M. Thomé, and M. V. Pereira, "An Aumann-Shapley approach to allocate transmission service cost among network users in electricity markets," IEEE Transactions on Power Systems, vol. 22, no. 4, pp. 1532-1546, 2007.

[124] R. Bhakar, V. S. Sriram, N. Prasad Padhy, and H. O. Gupta, "Network embedded cost allocation: a game-theoretic approach," in Proceedings of the 32nd National Systems Conference, NSC, December 2008.

[125] R. Bhakar, V. S. Sriram, N. P. Padhy, and H. O. Gupta, "Probabilistic game approaches for network cost allocation," IEEE Transactions on Power Systems, vol. 25, no. 1, pp. 51-58, 2010.

[126] J. M. Zolezzi and H. Rudnick, "Consumers coordination and cooperation in transmission cost allocation," in Proceedings of the IEEE Power Tech Conference, vol. 3, p. 7, Bologna, Italy, June 2003.

[127] H. Singh, S. Hao, A. Papalexopoulos, and M. Obessis, "Cost allocation in electric power networks using cooperative game theory," http://www.eeeconsulting.net/pub_1/p1_costallocation .pdf.

[128] S. Balagopalan and V. S. Anooja, "Cooperative game theory for sharing transmission charges in electricity markets," in Proceedings of the IET Conference on Reliability of Transmission and Distribution Networks (RTDN '11), pp. 1-6, London, UK, November 2011.

[129] F. D. Galiana, A. J. Conejo, and H. A. Gil, "Transmission network cost allocation based on equivalent bilateral exchanges," IEEE Transactions on Power Systems, vol. 18, no. 4, pp. 14251431, 2003.

[130] J. O. F. Silva, P. Cuervo, and J. C. Mateus, "Revenue adequacy procedure in congested networks through equivalent bilateral exchanges," in Proceedings of the CIGRE/IEEE PES International Symposium, pp. 44-51, New Orleans, La, USA, October 2005.

[131] J. O. F. Silva and P. Cuervo, "Allocating congestion management costs through use-based principle of equivalent bilateral exchanges," in Proceedings of the 5th International Conference on the European Electricity Market, EEM, pp. 1-6, Lisbon, Portugal, May 2008.
[132] J. C. Mateus and P. C. Franco, “Transmission loss allocation through equivalent bilateral exchanges and economical analysis," IEEE Transactions on Power Systems, vol. 20, no. 4, pp. 17991807, 2005.

[133] S. Nouri and S. Jadid, "Transmission network loss allocation via equivalent bilateral exchanges principle and genetic algorithm," in Proceedings of the 2nd IEEE International Power and Energy Conference (PECon '08), pp. 1311-1316, Johor Bahru, Malaysia, December 2008. 

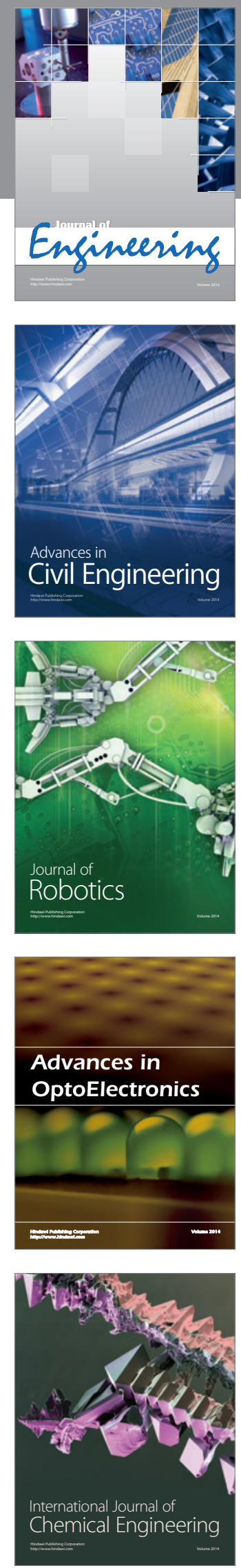

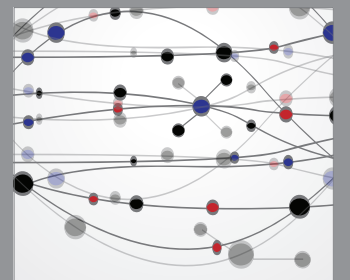

The Scientific World Journal
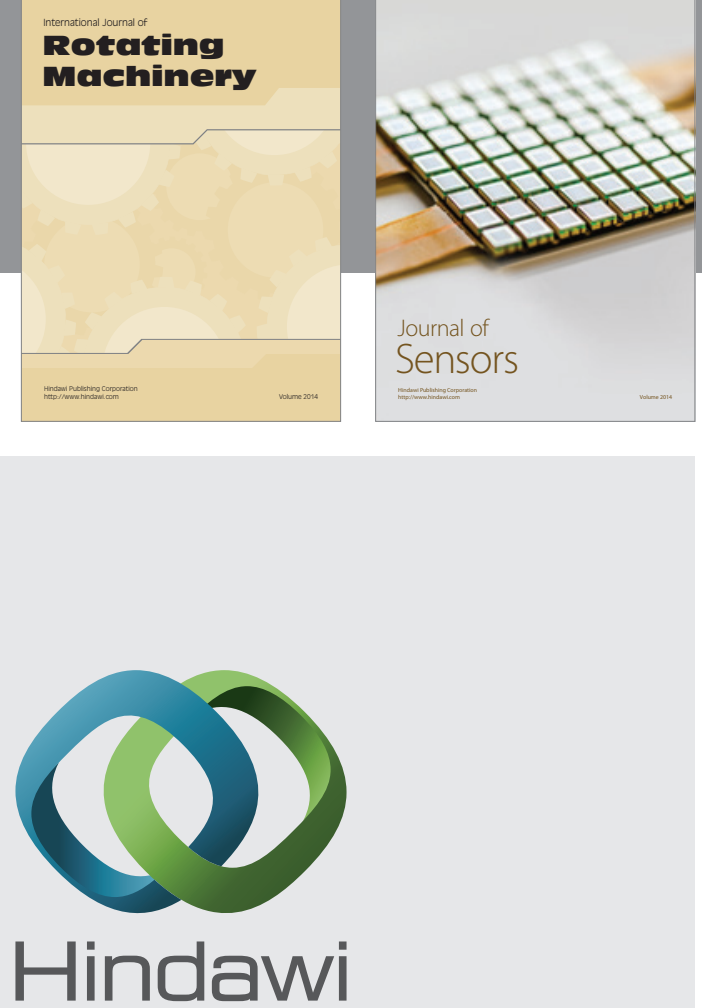

Submit your manuscripts at http://www.hindawi.com
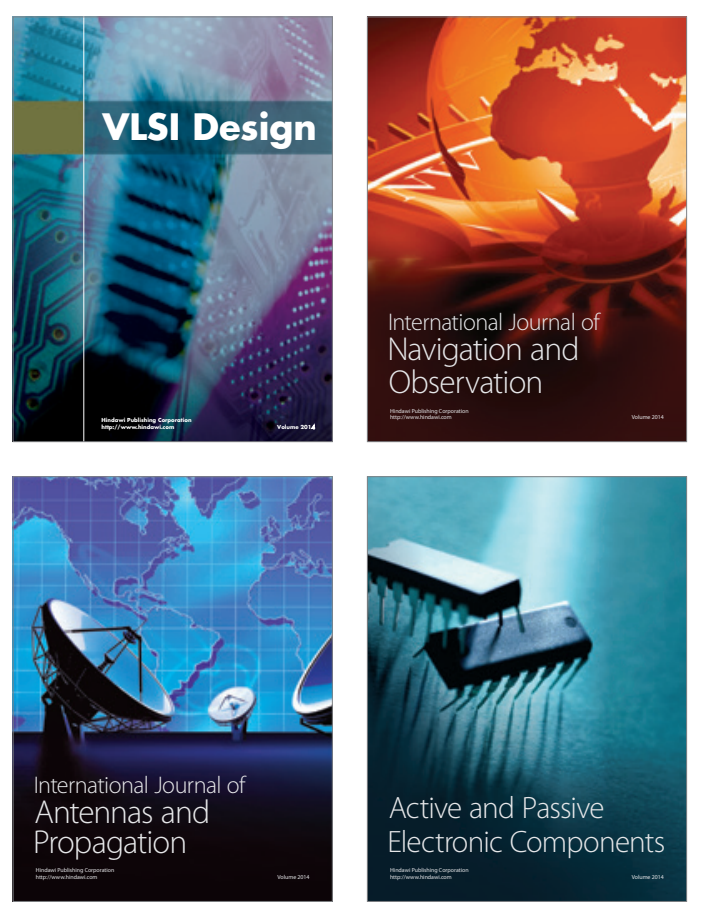
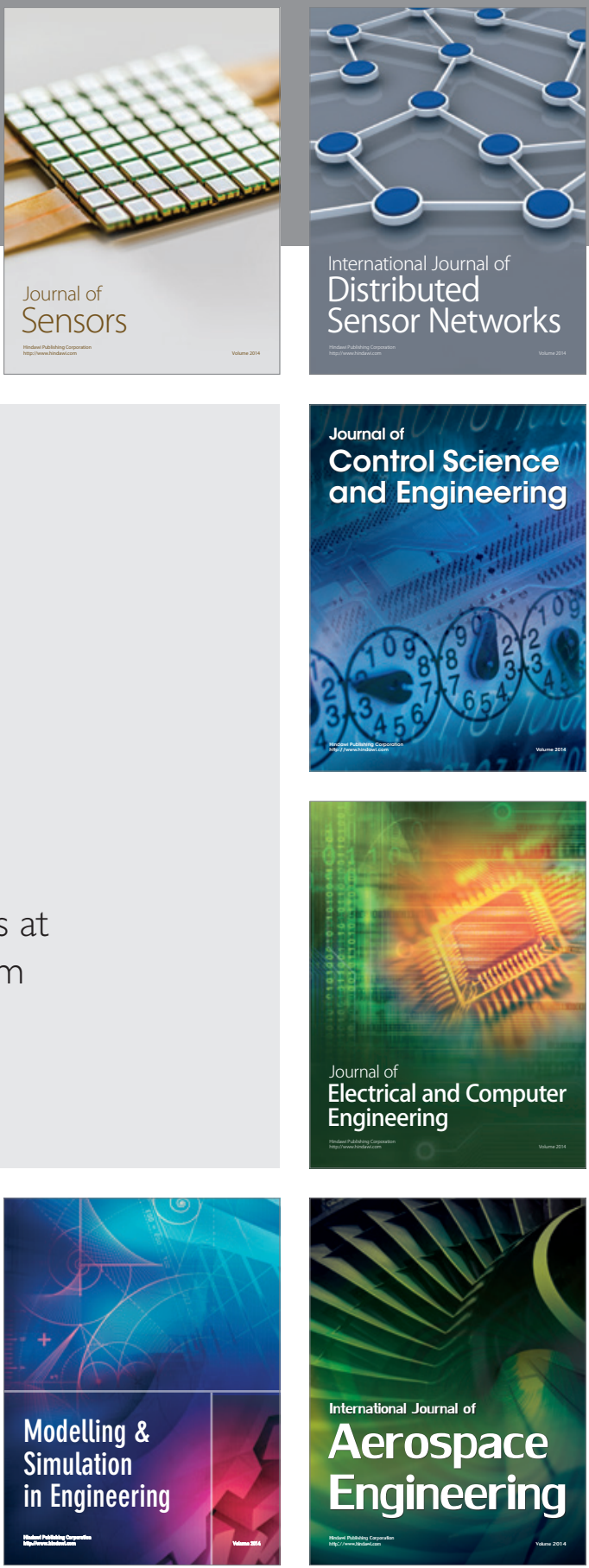

Journal of

Control Science

and Engineering
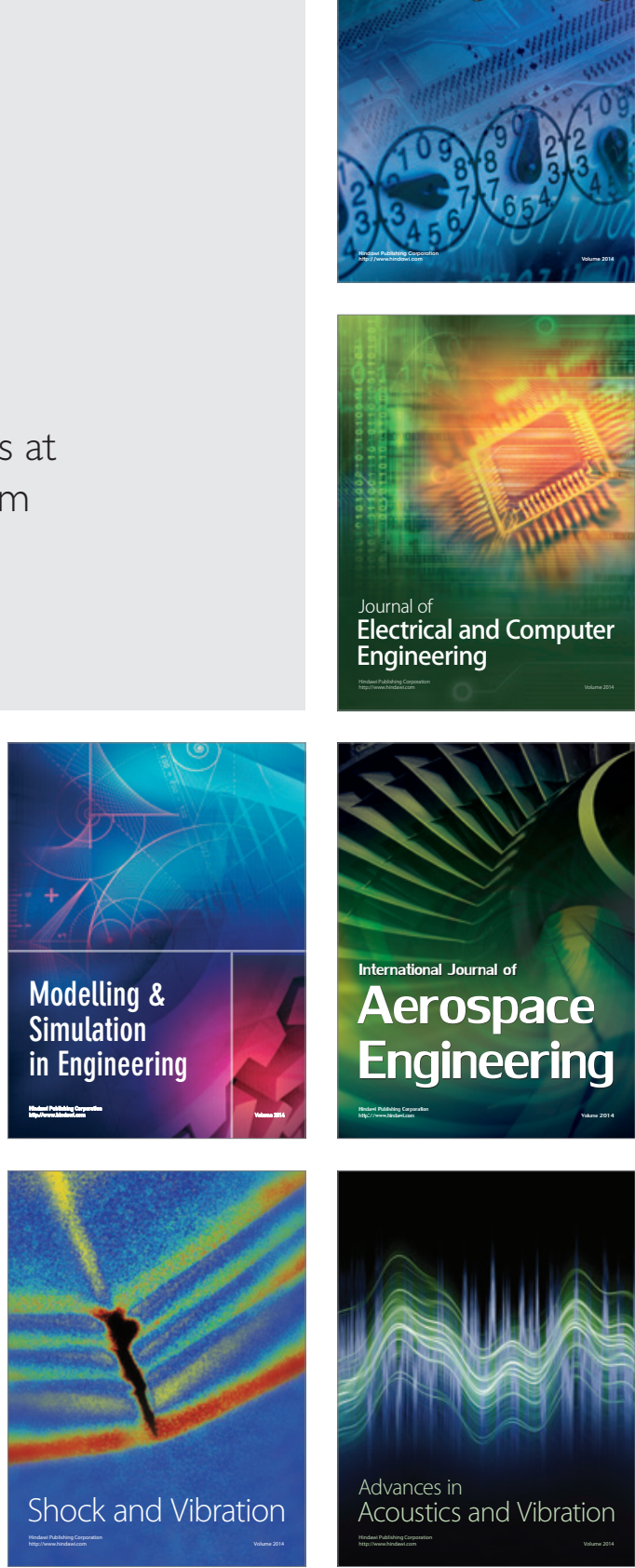